\title{
Regeneration of static-load-degenerated articular cartilage extracellular matrix by vitamin $C$ supplementation
}

\author{
Garima Sharma $\cdot$ R. K. Saxena $\cdot$ Prashant Mishra
}

Published online: 9 April 2009

(C) Springer-Verlag 2009

\section{Erratum to: Cell Tissue Res \\ DOI 10.1007/s00441-008-0666-9}

I would like to extend my apologies to the readership of the journal and the scientific community for having published an incorrect interpretation of electron microscopic images. Figure 5 of the above publication does not show chondrocytes. Absence of nuclei, mitchondria, and cytoskeletal structures, together with a cell wall and cytoplasm typical of bacteriae, support the notion that the electron micrographs show bacteriae, but definitely no chondrocytes.

Klaus Unsicker

Coordinating Editor

The online version of the original article can be found at http://dx.doi. org/10.1007/s00441-008-0666-9

\section{G. Sharma $\cdot$ R. K. Saxena}

Centre for Biomedical Engineering,

Indian Institute of Technology Delhi,

Hauz Khas, New Delhi 110016, India

G. Sharma $\cdot$ P. Mishra $(\bowtie)$

Department of Biochemical Engineering and Biotechnology,

Indian Institute of Technology Delhi,

Hauz Khas, New Delhi 110016, India

e-mail: pmishra@dbeb.iitd.ernet.in 